Summer 2008

\title{
Patents and Traditional Medicine: Digital Capture, Creative Legal Interventions and the Dialectics of Knowledge Transformation
}

Chidi Oguamanam

Dalhousie Law School

Follow this and additional works at: https://www.repository.law.indiana.edu/ijgls

Part of the Intellectual Property Law Commons, International Law Commons, and the Medical Jurisprudence Commons

\section{Recommended Citation}

Oguamanam, Chidi (2008) "Patents and Traditional Medicine: Digital Capture, Creative Legal Interventions and the Dialectics of Knowledge Transformation," Indiana Journal of Global Legal Studies: Vol. 15 : Iss. 2 , Article 3.

Available at: https://www.repository.law.indiana.edu/ijgls/vol15/iss2/3

This Article is brought to you for free and open access by the Law School Journals at Digital Repository @ Maurer Law. It has been accepted for inclusion in Indiana Journal of Global Legal Studies by an authorized editor of Digital Repository@Maurer Law. For more information, please contactrvaughan@indiana.edu.

\section{$\Psi$}

JEROME HALL LAW LIBRARY

INDIANA UNIVERSITY

Maurer School of Law
Blooming ton 


\title{
Patents and Traditional Medicine: Digital Capture, Creative Legal Interventions, and the Dialectics of Knowledge Transformation
}

\author{
Chidi Oguamanam*
}

\begin{abstract}
ABstract

This article examines the debate over the exclusion of indigenous or local knowledge forms from the global intellectual property system, and some of the current attempts to solve this problem. Using the lens of cultural cosmopolitanism, the article highlights important trends in the dialectics of developing countries' engagement with intellectual property and other collateral knowledge protection systems. The three sites at which this significant development is unfolding are: (1) the digitization of traditional medicinal knowledge through India's traditional knowledge digital library (TKDL) project; (2) a recent attempt at incorporating innovations in Chinese Herbal Medicine (CHM) in Taiwanese patent law; and (3) efforts to enshrine disclosure of origin requirements $(D R s)$ in patent applications, and developments around geographical indications $(G I s)$.
\end{abstract}

\section{INTRODUCTION}

The alternative to the divisiveness of one preeminent categorization is not any unreal claim that we are all much the same. That we are not. Rather, the main hope of harmony in our troubled world lies in the plurality of our identities, which cut across each other

* LL.M, Ph.D. (British Columbia), Director, Law and Technology Institute, Dalhousie Law School, Halifax, Nova Scotia, Canada. Aspects of this paper were presented at the 2008 Intellectual Property Scholars Roundtable, Drake University, Des Moines, Iowa. Thanks to Professor Peter K. Yu, Director, Intellectual Property Law Center at Drake, for inviting me to the Roundtable and to all participants for their feedback. I also thank Jerry I.-H. Hsiao of Queen Mary Intellectual Property Research Institute, University of London, for his assistance in the course of my research on Taiwanese patent law. This paper is dedicated to Professor Teresa Scassa. 
and work against sharp divisions around one single hardened line of vehement division....'

Indigenous and local communities and developing countries in general have a complex relationship with the intellectual property system. ${ }^{2}$ From suspicion and trepidation, they engage that system reluctantly, but often proactively. Beyond intellectual property, they are also active participants in the debates around other peripheral knowledge protection systems which are either collateral to or independent of the intellectual property framework. Like the "dialectics of the colonized mind,"' indigenous peoples' attitude toward intellectual property reflects both admiration, and disaffection or resistance. For instance, according to Madhavi Sunder, they "focus simultaneously on a defensive intellectual property policy, limiting rights in the context of essential medicines, and an offensive intellectual property policy, seeking to expand intellectual property protection for 'poor people's knowledge' through mechanisms to protect biological diversity, traditional knowledge, and geographical indications."

Popular accounts of the indigenous and local communities' ambivalent relationship with the intellectual property system reflect a hopeless state of frustration. ${ }^{5}$ The dominant issues revolve around the suitability of the intellectual property scheme to the overall conceptual thrust of indigenous or local knowledge systems. Next to that is the search for suigeneris knowledge protection mechanisms that are amenable to indigenous knowledge or, in the alternative, the quest for the re-calibration of intellectual property philosophy to accommodate the exi-

1. Amartya Kumar Sen, Identity and Violence 16 (2006).

2. For analytical convenience, references to indigenous peoples and/or local communities in this paper apply to such categories in both developing and developed countries, and, in appropriate places, emphasis is placed on the exigencies of developing countries without a conscious attempt to distinguish between those countries and their indigenous and local communities.

3. Sen, supra note 1 , at 85 .

4. See Madhavi Sunder, IP3, 59 Stan. L. Rev. 257, 297-98 (2006) (Sunder's observation is specifically directed to developing countries but it is aptly relevant to indigenous communities in the developed world).

5. See e.g., Naomi Roht-Arriaza, Of Seeds and Shamans: The Appropriation of the Scientific and Technical Knowledge of Indigenous and Local Communities, 17 MicH. J. INT'L L. 919,953-58 (1996); Christine Haight Farley, Protecting Folklore of Indigenous Peoples: Is Intellectual Property the Answer?, 30 Conn. L. Rev. 1, 12-40 (1997). See also Valuing Local Knowledge: Indigenous Phople and Intellectual Property Rights (Stephen B. Brush \& Doreen Stanbinky eds., 1996) (examining proposals to treat cultural and indigenous knowledge as a form of intellectual property). 
gencies of the so-called non-Western knowledge forms. ${ }^{6}$ Even then, the suspicion remains strong in developing countries and indigenous and local communities about the long-term implication of unwholesome "appropriation of local knowledge" into the intellectual property system. ${ }^{7}$

A combination of factors, such as economic globalization, progress in genetic research for food, drugs, and agriculture, as well as the escalating phenomenon of biopiracy, ${ }^{8}$ has made indigenous and local communities' ambivalence regarding intellectual property an ill affordable option. ${ }^{9}$ These trends, aided by intellectual property, each facilitate a unidirectional transfer of biological resources and associated knowledge systems from developing countries to Western industrial complexes with no benefit to their centers of origin. ${ }^{10}$ Consequently, developing countries have resorted to diverse strategies, nationally and internationally, for the protection of various aspects of their knowledge forms."

This article attempts to depart from the grim but popular accounts of developing countries' and indigenous and local communities' troubled experiences and struggles with intellectual property and other mainstream knowledge protection strategies. Using the lens of cultural cosmopolitanism, which reflects the blurring of absolute distinctions across knowledge systems, this article highlights some important trends in the dialectics of developing countries' engagement with intellectual property and other collateral knowledge protection systems. Drawing

6. See Dan Leskien \& Michael Flitner, Intellectual Property Rights and Plant Genetic Resources: Options for a Sui Generis System, 6 Issues in Genetic Resources 1, 43-65 (1997); Ikechi Mgbeoji, Patents and Traditional Knowledge of the Uses of Plants: Is a Communal Patent Regime Part of the Solution to the Scourge of Bio Piracy?, 9 Ind. J. Global. Lecial Stud. 163, 173-75 (2001); Peter Drahos, Indigenous Knowledge, Intellectual Property and Biopiracy: Is a Global Bio-Collecting Society the Answer?, 22 Eur. INtell. Prop. Rev. 245, 247-50 (2000).

7 See Lester I. Yano, Comment, Protection of the Ethnobiological Knowledge of Indigenous Peoples, 41 UCLA L. Rev. 443, 485-86 (1993). See also Arun Agrawal, On Power and Indigenous Knowledge, in Cultural and Spiritual Values of Biological Diversity 177 (Darrel A. Posey ed., 2000).

8. Generally, biopiracy is a loose reference to unidirectional appropriation of biocultural knowledge and associated biological resources of indigenous and local communities by external interests or second comers.

9 See Chidi Oguamanam, Intellectual Property Rights in Plant Genetic Resources: Farmers' Rights and Food Security of Indigenous and Local Communities, 11 Drak E J. Agric. L. 273, 278 (2006).

10. Anupam Chander \& Madhavi Sunder, The Romance of the Public Domain, $92 \mathrm{C}_{\mathrm{AL}}$. L. Rev. 1331, 1346-47 (2004).

11. For an overview of these strategies and institutional sites in which they are canvassed, see Laurence R. Helfer, Regime Shifting: The TRIPS Agreement and New Dynamics of International Intellectual Property Lawmaking, 29 Y ALE J. INT'L L. 1, 10-52 (2004) and Ruth L. Okediji, Back to Bilateralism? Pendulum Suings in International Intellectual Property Protection, 1 U. Ottawa L. \& ТЕСН. ). 125, 136-42 (2004). 
from ongoing developments, especially those concerning traditional medicine, I argue that one of the major, albeit unsuspecting, outcomes of the pressure which local knowledge poses for the intellectual property system is that it has opened an opportunity for conversation across knowledge systems, strategically empowering indigenous or local knowledge in the process. I am more concerned with the symbolic ramifications of this trend than with its overall translation and impact in regard to actual leveraging of traditional knowledge forms. The significance of the trend lies in the empirical support and irresistible credence it bequeaths to the thesis of cultural cosmopolitanism. Also, it points to the importance of reflective consciousness regarding the limits of the overarching binary classification of knowledge systems into the Western and non-Western that corresponds, even if arguably, to the cosmopolitan and local epistemic divide.

For the purpose of the present exercise, this article does not explore the controversies over the merits or demerits of the presumed cosmopolitan and local status of Western and non-Western knowledge systems. ${ }^{12}$ Nor does it seek to inquire into the presumed and often contested scientific status of the two knowledge systems. ${ }^{13}$ In contemporary times, the deceptive alliance between appearance and reality, which is analogous to law's perception of possession and ownership, helps to sustain these presumptions. Categorizations of the status of "knowledge" are hardly absolute, ${ }^{14}$

12. In diverse contexts, cosmopolitanism itself is a contested term, especially when used in juxtaposition with "local." For example, in some quarters, cosmopolitanism is a reference to creolization or hybridization of knowledge or cultural practices as counterpoint to homogeneity; in other cases, it depicts an unending state of conflict and struggle for emancipation between local and "translocal" or dominant tendencies. See generally Will Kymlicka, Multicultural Odysseys: Navigating the New International Politics of Diversity (2007) (identifying the moral dilemmas and political complexities raised by international efforts to diffuse multiculturalism); WILL KyMLICKa, LiberalISM, Community and Culture (1989) (arguing that the resources available within the liberal view of culture have been misunderstood); Boaventura De Sousa Santos, Toward a New Common Sense: Law, Science and Politics in the Paradigmatic Transition (1995); Ulf Hannerz, Cosmopolitans and Locals in World Culture, in Global Culture: Nationalism, Globalization and MoDERnity 237-51 (Mike Featherstone ed., 1990) (discussing the globalization of culture); Jeremy Waldron, Minority Cultures and Cosmopolitan Alternatives, in The Rights of Minority Cultures 93 (Will Kymlicka ed., 1995) (exploring the tension between what is implicit in the affirmation of cosmopolitanism and the individual views created out of cultural immersion).

13. See generally Local Science vs. Global Science: Approaches to Indigenous Knowledge in International Development (Paul Sillitoe ed., 2007) (arguing for the need to acknowledge that the social positioning of knowledge is culturally embedded).

14. See Chidi Oguamanam, International Law and Indigenous Knowlenge: Intellectual Property, Plant Biodiversity, and Traditional Mrdicine 15-18 (2006); Arun Agrawal, Dismantling the Divide Betueen Indigenous and Scientific Knowledge, 26 Dev. \& Change 413, 416-20 (1995); Arun Agrawal, Indigenous and Scientific Knouledge: Some Critical Comments, 3 Indigenous 
and, for good reasons, they are open to continued interrogation. For example, despite the significant and historic contributions of Arab and Muslim societies to science and mathematics, Amartya Sen observes that "crude classifications have tended to put science and mathematics in the basket of 'Western science,' leaving other people to mine their pride in religious depths." ${ }^{15}$ The same is true of the appropriation of Egyptian and African contributions to what is now called "Western medicine."16

Cultural cosmopolitanism itself is a postmodern concept that inherently implicates the symbiotic relationship between knowledge and culture. ${ }^{17}$ It stems mainly from contemporary anthropologists', legal anthropologists', and political philosophers' reservations about the rigid classification or bifurcation of knowledge systems. ${ }^{18}$ Their central argument is that knowledge and culture are not static; they are constantly negotiated, and they evolve in a processual manner. The evolution of knowledge follows a pattern of "creative mixing"-creative borrowing and creolization across knowledge systems. ${ }^{19}$ This trend is integral to the ubiquitous phenomenon of globalization.

Cultural cosmopolitanism is an attractive theoretical alternative to the now discredited notion of culture as a static and isolated phenomenon which has lost favor in anthropological circles. That discredited approach provided intellectual support for rigid and near absolute demarcations of knowledge frameworks into, for example, Western scientific and non-Western or local epistemic systems. In its broad application, cultural cosmopolitanism problematizes absolute qualifications or claims to knowledge that are insensitive to the traffic and exchange of informa-

Knowledge And Development Monitor 1, 2-4 (1995), available at http://www-personal.umich. edu/ arunagra/papers/IK\%20 Monitor\%203(3)\%20Angrawal.pdf.

15. SEN, supra note 1 , at 15.

16. See Collins O. Airhihenduma, Health and Culture: Beyond the Western Paradigm 51-54 (1995); Cheikh Anta Diop, Precolonial Black Africa: A Comparative Study of the Political and Social Systems of Europe and Black Africa, From Antiquity to the Formation of Modern States 205-206 (Harold J. Salemson trans., 1987) (pointing out that empirical medicine, including diverse forms of surgical procedures like cataract, shrapnel and bullet extraction, wound cauterization, etc. utilizes aspects of African medical traditions from antiquity).

17. See generally Local Science vs. Global Science, supra note 13.

18. See, e.g., Olufunmilayo B. Arewa, TRIPS and Traditional Knowledge: Local Communities, Local Knowledge, and Global Intellectual Property Frameworks, 10 MA Ro. INTELL. Prop. L. Rev. 155, 164-66 (2006); Michael F. Brown, Can Culture Be Copyrighted?, 39 Current Anthropology 193, 197-99 (1998); Olufunmilayo B. Arewa, Piracy, Biopiracy and Borrowing: Culture, Cultural Heritage and the Globalization of Intellectual Property, 68-72 (Berkeley Electronic Press, Working Paper No. 1114, 2006) available at http://law.bepress.como/expresso/eps/11141 [hereinafter Piracy, Biopiracy and Borrouing]. See generally supra note 12 and accompanying text.

19. Brown, supra note 18 , at 196. 
tion across knowledge or cultural systems. ${ }^{20}$ Specifically, it has been used to interrogate indigenous peoples' exclusive claims over their traditional knowledge via intellectual property rights. ${ }^{21}$ Despite its persuasion, the notion of cultural cosmopolitanism could not obliterate logical markers that distinguish knowledge systems, no matter how inconclusive they may be. ${ }^{22}$ However, it calls attention to the limits of a narrow and "single hardened line of vehement division"23 across knowledge systems and the potential of such systems to cut across or interact with one another for the collective benefit of humanity.

The bifurcation of knowledge systems along Western and non-Western categories and their cosmopolitan and local correlation are symbolically illustrated in the distinction usually made between Western orthodox medicine and traditional medicine, ${ }^{24}$ broadly construed. Writing in specific reference to Chinese Herbal Medicine (CHM), Jerry I.-H. Hsiao makes the following observation, which is largely true for the rest of traditional medicine or complementary and alternative medicine (CAM). He notes:

CHM differs from Western medicine in its basic orientation, physiological theories, etiology, diagnostics, therapeutics and pharmacology. The major difference between $\mathrm{CHM}$ and Western medicine is their fundamental difference in medical theories. While Western medicine adopts the Cartesian reductionism approach separating the body and the mind, CHM is holistic. CHM is an art as well as a science. ${ }^{25}$

20. See Oguamanam, supra note 9, at 298-300.

21. See Piracy, Biopiracy and Borrowing, supra note 18 , at $65-68$. See generally Brown, supra note 18 (assessing the legal schemes proposed to control cultural appropriation).

22. See Chidi Oguamanam, Local Knowledge as a Trapped Knowledge: Intellectual Property, Culture, Power and Politics, 11 J. World Intell. Prop. 29 (2008).

23. SEN, supra note 1 , at 16.

24. Generally, traditional medicine is also referred to as Complementary and Alternative Medicine (CAM). Traditional medicine or CAM is not, however, a single category. It is a federation of medical systems which are rooted in strong independent or interdependent theories and philosophies of medicine that are readily distinguishable from western orthodox medicine. According to the U.S. National Centre for Complementary and Alternative Medicine (which is part of the National Institutes of Health), "CAM is a group of diverse medical and health care systems, practices, and products that are not presently considered to be part of conventional medicine." NCCAM, What is CAM? 1 (Feb. 2007), http://nccam.nih.gov/health/whatiscam/pdf/D347.pdf.

25. Jerry I.-H. Hsiao, Patent Protection for Chinese Herbal Medicine Product Invention in Taiwuan, 10 J. World Intell. Prop. 1, 4 (2007) (citation omitted). 
Similarly,

in traditional therapeutic systems, humanity is an integrated being; united in mind, body and soul. The unity of mind and body is linked to the desired unity between the individual and her larger community, as the primary aim of traditional therapy. Treatment $\ldots$ is approached from a holistic perspective. ${ }^{26}$

Ironically, despite being the source of medical relief for 80 percent of the global population, traditional medicine and its associated knowledge are perceived as a form of local knowledge, in contrast to Western biomedicine. A number of factors account for the presumed local status of traditional medicine, and the cosmopolitan status of its Western counterpart. The most critical factor is the colonial hierarchy of culture and power in which non-Western peoples and their knowledge systems are treated with disdain and derogation. ${ }^{27}$ Other factors relate to the formal approach of biomedicine, manifested in part by its historical claims to being exclusively scientific and, by inference, universal in relation to other systems of medicine. ${ }^{28}$ Closely related to these is the association of science in general, and medical science in particular, with the "Western," especially in accordance with the Cartesian tradition. ${ }^{29}$ The strong global presence and visibility of all things "Western" is a logical, albeit questionable, basis of entitlement to cosmopolitanism.

Intellectual property, particularly the patent regime, is an important factor in

26. Chidi Oguamanam, Between Reality and Rhetoric: The Epistemic Schism in the Recognition of Traditional Medicine in International Law, 16 St. Thomas L. Rev. 59, 97 (2003). See also Bonnie B. O'Connor \& David J. Hufford, Understanding Folk Medicine, in Healing Logics: Culture and Medicine in Modern Health Belief Systems 13-19 (Erica Brady ed., 2001).

27. See Duncan Ivison, Postcolonial Liberalism 35 (2002); Piracy, Biopiracy and Borrowing, supra note 18, at 33-37; Oguamanam, supra note 22.

28. See Chidi Oguamanam, Biomedical Orthodoxy and Complementary and Alternative Medicine: Ethical Challenges of Integrating Medical Cultures, 12 J. Alternative \& Complementary Med. 577, 577 (2006); P.R. Wolpe, Alternative Medicine and the AMA, in The American Medical Ethics Revolution: How the AMA's Code of Ethics Has Transformed Physicians' Relationship to Patients, Professionals and Society 218 (R.B. Baker et al. eds., 1999).

29. René Descartes is a 16th century French philosopher who is credited with the exploration of the scientific method of reduction in the exploration of complex philosophical problems. This approach was very fundamental in the evolution of biomedicine through its treatment of the human body according to its component parts and offering its therapeutic approach as a targeted organismic intervention. This contrasts sharply with the holistic thrust of the diverse ideologies of traditional medicine. 
the privileging of Western medicine over traditional medical systems. ${ }^{30}$ However, methods of medical treatment are excluded from virtually all national patent regimes. ${ }^{31}$ Consequently, the impact of intellectual property on medical care delivery turns mainly on pharmaceutical innovations, including access to drugs, related products, and various other medical technological innovations other than methods of treatment. In traditional medicine, the pharmacological process involves mainly the exploitation of natural products such as plants, animals, and minerals in accordance with underlying theories of health and healing. ${ }^{32}$ In most cases, the holistic nature of traditional medicine means the fusion of the therapeutic with the pharmacological. ${ }^{33}$

Conversely, in Western medicine, the pharmacological and medical processes are separate. In accordance with the Cartesian approach, Western medicine is designed to identify, isolate, and purify the active substance, or create its synthetic alternative, with a view to pointedly account for its function in the therapeutic process. It also adopts an organismic account of disease and a reductionist understanding of the human anatomy as separate from the mind and as a component of diverse parts that can be targeted for therapeutic intervention. ${ }^{34}$

The methodological and ideological dichotomy between Western and traditional medicine resonates in the direct exclusion of traditional medicine from the patent process. ${ }^{35}$ In its checkered evolution in the West, the patent system is attuned to the processes and products of Western scientific innovation. Its technical details have little problem legitimizing pharmacological processes, products, and related innovations as a component of Western medicine. On the contrary, traditional medicine is a stranger to the patent process. Patent law's discrimination against forms of local knowledge fosters the notorious bifurcation of knowledge systems along Western (scientific) and non-Western (non-scientific) praxis. The

30. See Chidi Oguamanam, Localizing Intellectual Property in the Globalization Epoch: The Integration of Indigenous Knowledge, 11 Ind. J. Global Legal Stud. 135, 149 (2004).

31. See, e.g., Final Act Embodying the Results of the Uruguay Round of Multilateral Trade Negotiations, Apr. 15, 1994, Agreement on Trade-Related Aspects of Intellectual Property Rights, annex 1 C, art. 27, 33 I.L.M. 1125, 1208 (1994).

32. See Hsiao, supra note 25, at 4-5; O'Connor \& Hufford, supra note 26, at 29; Oguamanam, supra note 26, at 73-75. See generally Cecil G. Helman, Culture, Health and Illness (4th ed. 2000) (addressing the clinical significance of, and complex interactions between, health, illness and culture).

33. Oguamanam, supra note 14 , at 126.

34. Id. at 112-13. See also Oguamanam, supra note 26, at 96-98.

35. Oguamanam, supra note 26, at 112-13; Oguamanam, supra note 30, at 135-36; Yano, supra note 7, at 444-45; Agrawal, supra note 7, at 177-78. 
failure of the intellectual property system, especially the patent domain, to take traditional medicine and traditional knowledge seriously has been a source of disquiet in the world of indigenous and local communities and in the developing countries. ${ }^{36}$ It reinforces the distrust accorded to the current intellectual property regime and, simultaneously, raises passion and pressure for the revision of its conceptual framework in a manner typical of the dialectics of non-Western people's attitude to the intellectual property system.

Intellectual property's hardening of the stubborn division between Western medicine and biomedicine is not sensitive to the reality of cultural cosmopolitanism and creolization in the medical knowledge arena. However, developments in the traditional medicine and genetic resources arena in the last five years suggest that developing countries have adopted a radically different strategy in their approach to intellectual property which may have positive implications for local knowledge. ${ }^{37}$ Unconsciously, they have sought to renegotiate the so-called local status of traditional medicine through foisting the latter on the formal patent system in what translates into a direct encounter between the local and the cosmopolitan. In this way, they not only seek to empower traditional medicine but, by default, they confront the intellectual property system with the reality of cultural cosmopolitanism and the processual evolution of knowledge. In the following three sections, I explore the sites for this revolutionary strategy, highlighting its significance as modest yet constituting a paradigmatic shift in indigenous and

36. This vacuum in the intellectual property system is one of the pivotal sources of tension in the international intellectual property lawmaking process. It often pitches developing and developed countries against each other. In the last decade, the tensions have been heightened by the concerted pressure exerted by developing countries for a review of the TRIPS Agreement, among other things, to accommodate the contributions of the knowledge of indigenous and local communities. Recent discourses of this trend are captured by the concept of "regime shifting" or "regime tension" in the intellectual property system. See, e.g., Marney L. Cheek, The Limits of Informal Regulatory Cooperation in International Affairs: A Review of the Global Intellectual Property System, 33 Geo. wash. Int'L L. Rev. 277, 293-95 (2001); Helfer, supra note 11 at 4-6; Chidi Oguamanam, Regime Tension in the Intellectual Property Rights Arena: Farmers' Rights and Post-TRIPS Counter Regime Trends, 29 Dalmousie L. J. 413 (2006); Okediji, supra note 11, at 128-29; Ruth L. Okediji, The International Relations of Intellectual Property: Narratives of Developing Countries Participation in the Global Intellectual Property System, 7 Sing. J. Inr'L \& Comp. L. 315, 337-39 (2003); Peter Yu, Current and Cross-Currents in the International Intellectual Property Regime, 38 Lov. L.A. L. Rev. 323, 373-74 (2004). Furthermore, the growing literature on biopiracy discusses and assails the lack of entrenchment of local knowledge in the international intellectual property system. See, e.g., Ikechi Mgbeoji, Global Biopiracy: Patents, Plants and Indigenous Knowledge 11 (2006).

37. This is demonstrated in this article through examples drawn from the Traditional Knowledge Digital Library (TKDL) project, the Disclosure of Origin (DRs), Geographical Indications (GIs), and various other legal interventions. 
local communities' approach to, and experience with, the intellectual property establishment. It remains to be seen to what extent this strategy could potentially position local knowledge within the structure, content, and conceptual framework of conventional intellectual property.

This article will discuss the three sites at which this significant development is unfolding: 1) the digitization of traditional medical medicine through India's traditional knowledge digital library (TKDL) project (Part I);2) a recent attempt at incorporating innovations in CHM in Taiwanese patent law (Part II); and 3) efforts to enshrine disclosure of origin requirements (DRs) in patent application, and developments around geographical indications (GIs) (Part III).

\section{Digital Capture of Traditional Medicine}

\section{A. The Indian Initiative}

India, indeed, the Indian subcontinent, has a rich heritage in traditional medicinal knowledge. This heritage derives from multiple medicinal traditions, including Ayurveda, homeopathy, naturopathy, Siddha, Unanani, and Yoga. ${ }^{38}$ Even though the bulk of this knowledge has been handed down by oral tradition, significant parts of it are described in diverse but usually inaccessible classical literature in different traditional or local languages such as Hindi, Sanskrit, Urdu, Tamil, and others. Despite their inaccessibility, their age-long codification warrants according them public domain status. In recent times, transnational pharmaceutical corporations and research institutions have exploited India's medicinal heritage through the patent system. Notable examples include the turmeric, basmati, and neem patents, the applications for which were the subject of controversy at the United States Patent and Trademark Office (USPTO), the European Patent Office (EPO), and elsewhere. ${ }^{39}$ The experience became a wake-up call for India to address the nagging issue of the exploitation of its traditional medicinal heritage and the scourge of biopiracy, just like the Soviet launch of the Sputnik

38. See Oguamanam, supra note 14 , at 120-21.

39. See, e.g., Arewa, TRIPS and Traditional Knowledge, supra note 18, at 170-79 (providing detailed accounts of such biopiracy); Murray P. Eiland, Patenting Traditional Medicine, 89 J. Pat. \& Trademark Off. Soc'y 45, 62-69 (2007); Emily Marden, The Neem Tree Patent: International Conflict Over the Commodification of Life, 22 B.C. INT'L \& Comp. L. Rev. 279 (1999) (discussing the neem tree patent). 
pushed America to seriously engage itself in the space race. ${ }^{40}$ India's experience is representative of a general trend in many developing countries with rich genetic resources and a traditional knowledge heritage.

India's response to the rampant biopiracy was the establishment of a defensive anti-appropriation strategy, the TKDL. This approach is an aggressive attempt to make previously inaccessible but codified Indian traditional medicinal knowledge available in digital form, so that patent examiners will have them handy as evidence of prior art (i.e., pre-existing knowledge), with a view to scuttling subsequent frivolous or biopiracy patents. ${ }^{41}$ The TKDL for India's systems of medicine is a massive state-sponsored interdisciplinary and interdepartmental project. It deploys the nation's wealth of human resources in medicinal knowledge systems, information technology, science, research, and bureaucracy. ${ }^{+2}$ According to its manifesto, "[t]he project ... involves the documentation of the knowledge available in [thel public domain on traditional knowledge from the existing literature related to Ayurveda, Unani and Siddha, in digitalized format in five international languages which are English, German, French, Japanese and Spanish. ${ }^{143}$ Throw-

40. The Sputnik was the first satellite to go beyond the earth's atmosphere and to orbit the planet. Its launch in October 1957 marked the beginning of the Space Age. It was a development that surprised the United States and pushed it to massively invest in science and technology that would assert the United States as a space power, a status which became a critical asset in the Cold War era.

41. The ambitious nature of the TKDL project is reflected in the intensity of its execution. In March 2007, Vinod Kumar Gupta reported the following statistics: Altogether, 148 books comprising 230 volumes of Ayurveda, Unani, Siddha and Yoga are being used for the TKDL project. Sixtyfour books of ninety volumes address Ayurveda with an anticipated 76,000 formulations. Unani TKDL is being derived from nineteen books of sixteen volumes. Both Ayurveda and Unani are in the same format and languages: Urdu, Arabic and Persian. Targeted formulations for Siddha are anticipated to be 12,000 derived from 45 Tamil texts of 53 volumes. Yoga TKDL is projected to be created from 150 posture images from 20 books and 24 million pages of information have been created out of the projected 31 million pages for 2007. These statistics show that in the five years in which TKDL has been active, it has exceeded most of its projections. See Vinod Kumar Gupta, India, TKDL: Definition and Classification of Intangible Cultural Heritage and Traditional Knowledge in the Context of Inventory Making, at I 20 (paper delivered at the Conference on Intangible Cultural Heritage and Intellectual Property Under the 2003 UN Convention for the Safeguarding of Intangible Cultural Heritage, New Delhi, India, March 25-27, 2007) (on file with author).

42. The collaborating institutions include the National Institute of Science Communication and Information Resources (NISCAIR), Council of Science and Industrial Research, Ministry of Science \& Technology and the Department of Ayurveda, Yoga, Unani, Siddha and Homeopathy (AYUSH) and Ministry of Health and Family Welfare. The project is being implemented at the NISCAIR. This author was privileged to participate in a guided tour of the TKDL in the spring of 2007 and had an opportunity to interview some staffers of the project at NISCAIR.

43. About TK DL, http://www.tkdl.res.in/tkdl/langdefault/common/Abouttkdl.asp?GL=Eng (last visited May 20, 2008). 
ing further light on the process, the Director of India's National Institute of Science Communication and Information Resources (NISCAIR) where the project is being implemented, V.K. Gupta, avers that the

TKDL database acts as a bridge between ancient traditional knowledge in the original languages (which may be in Hindi, Sanskrit, Urdu, Persian, Arabic, Tamil, etc.) and a patent examiner at a global level, since the database will provide information on modern as well as local names in a language and format understandable to patent examiners. The gap in prior art knowledge is minimized. The prior art has sufficient details on definitions, principles, and concepts to minimize the possibility of getting accepted minor insignificant modifications as novelty. ${ }^{44}$

Experts involved in the TKDL project include those in traditional knowledge classification and those knowledgeable in international patent classification practices. Also included are information technology (IT), language, and translation/ transcription experts. The IT experts create and provide technical support for the software and portal, while the traditional knowledge experts identify the formulations and incorporate them into the database after editing and verification.

India's decision to digitally document codified forms of its rich traditional medicinal heritage reflects the dialectics of developing countries' relationship with intellectual property and other knowledge protection systems. For instance, as a defensive mechanism, the TKDL's principal objective is to thwart potential or existing biopiracy patents or the tendency by second-comers or strangers to exploit India's traditional medicinal knowledge. India is, however, conscious of the potential intellectual property spin off of the project, especially through research and collaborative investment with foreigners interested in the use of the knowledge. ${ }^{45}$ Conceptually, therefore, the TKDL is not necessarily limited to a patentrelated prior art search. Conscious effort is directed at guarding against its subversion for potential counter-productive outcomes, such as when information in the TKDL is mismanaged in a way that facilitates biopiracy. In this regard, the access and use of the TKDL database is subject to an agreement that imposes a restrictive obligation on those who legitimately possess the database and are in a

44. See Gupta, supra note 41 , at If 9.

45. See id. 
position to make it accessible to third parties. ${ }^{46}$ Those in this privileged position include national and regional patent offices that need the TKDL databases to assist them in conducting prior art searches. ${ }^{47}$

One of the most significant contributions of the TKDL project within its short period of existence is its success in the proactive integration of its database "with the international intellectual property office activity of search and examination of the prior art search systems. ${ }^{148}$ For instance, the TKDL has improved on the problem associated with the classification system regarding the documentation of traditional knowledge. It has done this by creating a modern classification system fashioned after the framework of the International Patent Classification (IPC). The resulting classification, which so far covers only Unani and Ayurveda medicinal systems, is ambitiously called the Traditional Knowledge Resource Classification (TKRC). The IPC was created pursuant to the World Intellectual Property Organization (WIPO) administered multilateral treaty, the Strasbourg Agreement Concerning the International Patent Classification. ${ }^{49}$ It provides a hierarchical system in which technological or innovation categorics are divided into a range of sections, classes, and subclasses for easy identification in prior art examination. ${ }^{50}$ Patent offices of more than one hundred countries, other intellectual property regional offices, as well as the International Bureau of the WIPO and the Patent Corporation Treaty (PCT) rely on the IPC for prior art searches. ${ }^{51}$

The Indian initiative on the classification of traditional knowledge within the IPC has resulted in a detailed and improved IPC structure relating to traditional medicine. This includes the 2003 decision by the IPC Union to expand the classification of medicinal plants by about two hundred subgroups via the creation of a brand new group $(\mathrm{A} 61 \mathrm{~K} 36)$ and, perhaps most importantly, the linkage of IPC with the TKRC through a concordance table prepared by India. ${ }^{52}$ Currently, the

46. The NISCAIR has a sample access agreement as part of its brochure (on file with author).

47. As Traditional Knowledge Resource Classification (TKRC) becomes part of the International Patent Classification (IPC) system, the TK DL database is now an integral part of international and national patent administration.

48. Gupta, supra note 41, II 14.

49. Strasbourg Agreement Concerning the International Patent Classification, Mar. 24, 1971, 26 U.S.T. 1793.

50. See WIPO, Preface to the International Patent Classification, http://www.wipo.int/classifications/ ipc/en/general/preface.html (last visited July 12,2008) (discussing the eight sections (A-H), with an estimated 70,000 subclasses under the IPC).

51. Id.

52. This was a recommendation of a concerted committee of experts meeting of the IPC held in February 2001. The committee's decision was received positively by a WIPO-TK Task Force. The 
TKRC includes about 500 subgroups for medicinal plants, whereas IPC contained only one subgroup (i.e., A61K $35 / 78) .{ }^{53}$ In its operational modem system, the TKDL software incorporates the novel classification system, TKRC, and converts documented knowledge into target languages. In essence, medicinal formulations codified in ancient texts on Indian systems of medicine are transcribed or decoded into patent application formats in five so-called international languages under the meticulous supervision of scientists, technical officers, and distinguished experts in the particular systems of medicine. As opposed to transliteration,

[I]t [the software] does knowledge based conversion where data abstracted once is converted into several languages by using state of the art technology such as Unicode, XML and metadata methodology. Software also converts traditional terminology into [Western scientific] modern terminology, for example, Kumari (local name) to Aloe barbadensis, Masurika (Sanskrit name for a disease) to small pox, etc. ${ }^{54}$

In general, the TKDL software is designed to translate local and previously inaccessible information buried in India's traditional medicinal knowledge heritage into their modern scientific correlation, which patent examiners can readily use for prior art searches.

The digital capture of traditional medicinal knowledge has given new momentum to traditional knowledge in many respects. ${ }^{55}$ Interestingly, the popular and longer standing policy responses to intellectual property's problematic relationship with traditional knowledge remain inchoate and do not seem to have translated into any concrete results, let alone one with as much practical impact as the TKDL initiative. ${ }^{56}$ Specifically, the TKDL has fueled an epistemological encounter and dialogue

latter comprised the USPTO, EPO, China, Japan and India, which the IPC expert committee rallied when it was presented with India's proposal for the TK RC. See Gupta supra note 41, at II 3. The decision to link the TKRC with the IPC was taken at the 35th extraordinary meeting of committee of experts of the IPC Union in October 2004.

53. See Traditional Knowledge Digital Library User Manual 1 (a joint, undated publication of AYUSH, NISCAIR and the Controller General of Patents, Designs and Trade Marks, India) (on file with author).

54. Gupta, supra note 41 , at II 12.

55. See Chidi Oguamanam, Documentation/Digitizing of Traditional Knowledge and Intangible Cultural Heritage: Challenges and Prospects (forthcoming 2008) (discussing the pros and cons of traditional knowledge documentation, including the TKDL project).

56. For the most part, the literature focusing on this problem seems to dwell on the conceptual conflict between traditional knowledge and intellectual property rights, while making a case for 
between traditional medicine as a local knowledge form and its more cosmopolitan Western counterpart through the direct attempt to increase traditional medicine's stake within the patent system. Even though digitization of traditional medicine through the TKDL primarily aims at establishing aspects of its standing as prior art, it must be noted that preexisting patents, like those associated with Western medicine, are prima facie prior art. To that extent, the TKDL calibrates, or levels up, traditional medicine with its Western counterpart. This creates a semblance of psychological parity in favor of traditional medicinal knowledge vis-à-vis the extant recognition of Western scientific medicine under the patent regime. The difference is that while traditional medicine-related knowledge may be, at least in theory, freely accessible because it is part of the public domain, its Western biomedical or scientific counterpart is protected for the term of any applicable patent. Like the conventional patent system, the TKDL does not directly address the exclusive and proprietary aspects of traditional medicine. However, by creating a new classification system based on traditional medicine (i.e., the TKRC), and by informing the IPC and global patent literature, the TKDL "provides a bridge between modern science, modern medicines and traditional knowledge." ${ }^{\prime 7}$

Beyond bridging, the TKDL's adoption of the concordance methodology to entrench traditional medicine in the IPC system exposes the interaction, interrelationship, and creolization between Western medicine and traditional medicine in a way that blunts the sharp and uncritical loyalty to the prevalent rigid classification of the two knowledge forms. Even though the TKDL deals with codified information on traditional medicine in the public domain, as a permanent and growing feature of the global patent process, the TKDL promises to be of significant importance for the patentability of non-codified and independent traditional medicinal innovations.

In addition to being a new initiative that is barely five years old, the limitations of the TKDL are quite obvious. For instance, its associated TKRC is limited, at least, for now, to Ayurveda and Unani entries. Also, in its present form, it seems to narrowly focus on codified aspects of India's traditional medicinal system and does not address non-codified systems. Lastly, it is a state-sponsored initiative in which the extent of involvement of traditional custodians of the traditional medicinal heritages is not quite clear. Consequently, there is a limit to which the benefits of the digital capture of traditional medicine could be stressed. It is, however, evident that

expanding the intellectual property framework to accommodate local knowledge via, inter alia, a variety of sui generis models of intellectual property protection.

57. Gupta, supra note 41 , at If 7. 
TKDL offers symbolic credence to the theory of cultural cosmopolitanism, in addition to covertly opening up the patent system to traditional medicine in a local versus cosmopolitan encounter. In any case, the importance of TKDL appears to lie mostly in its potential to spread to other developing countries in a way that will further enable traditional knowledge to infiltrate the patent system.

\section{B. TKDL Outside India}

Indeed, since the Indian-initiated TKDL was established, it has proven to be inspirational to several countries and regional intellectual property and economic groups desirous of tackling the appropriation of their traditional knowledge resources. At present, India is providing support for the creation of TKDL for the South Asian Association for Regional Cooperation (SAARC) comprising Afghanistan, Bangladesh, Bhutan, India, Maldives, Nepal, Pakistan, and Sri Lanka. ${ }^{58}$ The Cameroon-based African Regional Industrial Property Organization (ARIPO) has also expressed interest in an African regional TKDL..$^{59}$ Several individual countries, including South Africa, Mongolia, and Thailand have expressed the interest to engage in similar national initiatives. ${ }^{60}$ Thus, despite its present and inherent practical and conceptual limitations, the TKDL is a potential mechanism to aid the emancipation of traditional knowledge and propel it into the conventional intellectual property system. In a way, it also demonstrates the practical relevance of the cultural cosmopolitanism thesis in the medical field.

Because it directly targets the scourge of biopiracy, the Indian TKDL initiative resonates with the majority of gene-rich developing countries. Other attempts to directly engage local knowledge with the intellectual property system are exemplified in the national initiatives of individual countries. Tackling biopiracy is not necessarily the motivation for this approach, in which the affected countries are determined to work within the framework of national patent laws and other nuanced policy options to empower traditional medicine. As demonstrated in the following discussions of the developments in China, Taiwan, and elsewhere, each country's approach is dictated by its peculiar or strategic national interest and comparative advantage.

58. For information on this regional organization, see http://www.saarc-sec.org/main.php (last visited May 20, 2008). See also Eiland, supra note 39, at 65.

59. See Ocunmanam, supra note 14 , at 89.

60. See T.V. Padma, Digital Library to Protect Indigenous Knowledge (Jan. 10, 2005), http://www. scidev.net/en/news/digital-library-to-protect-indigenous-knowledge.html. 


\section{China and Taiman: \\ Of Mixed Signals and Creative Legal Intervention}

\section{A. China: A Case of Mixed Signals}

Like India, China is a global leader in traditional medicinal practices. China's rich traditional medicinal heritage has a complicated history. ${ }^{61}$ A substantial part of Traditional Chinese Medicine (TCM) is based on rational theoretical principles which are also codified in several Chinese medical classics. ${ }^{62}$ TCM has often been distinguished from the medical traditions of Chinese national minorities such as those of Tibet and Mongolia. ${ }^{63}$ A combination of factors, including its deep theoretical foundation, secular nature, and codified status, tends to distinguish TCM from other forms of indigenous, folk, or traditional medical systems. ${ }^{64}$ China does not seem to have developed a keen interest in the documentation of its rich TCM, which also flourishes in the rest of East Asia, including Hong Kong, Taiwan, Japan, and the Koreas. In comparison to other traditional medical systems, TCM is reasonably integrated with conventional medicine, this being facilitated by its rationalism, among other considerations. Indeed, the pursuit of integration with conventional medicine, including the latter's scientific techniques, is the focus of TCM in contemporary times. In 2004, the Chinese government embarked on an aggressive system of "scientification" of TCM along the patterns of the integration strategy. That year,

the Chinese Ministry of Science and Technology ... made the modernization of [traditional medicines (TM)] one of the 12 main

61. See Oguamanam, supra note 14, at 121; Wang Pei, Traditional Chinese Medicine, in Traditional Medicine and Health Care Coverage 68, 68-75 (Robert H. Bannerman et al. eds., 1983).

62. The U.S. National Library of Medicine (NLM), which is part of the National Institutes of Health (NIH), has an online exhibit of the Classics of Traditional Chinese Medicine. For a sample of this rich resource, see http://www.nlm.nih.gov/hmd/chinese/books.html (last visited May 21, 2008).

63. For instance, Taiwan's Draft CHM Invention Patent Guideline does not include Tibetan and Mongolian traditional medicine as part of TCM. See Draft CHM Invention Patent Guideline (2002), available at http://www.tipo.gov.tw/patent/patent_law/examine/patent_law_3.asp [hereinafter Draft Guideline].

64. See Oguamanam, supra note 14 , at 121 (referring to the sophistication of TCM as documented since the Zhou dynasty and broadly delivered in four departments of medical specialty, namely nutrition, internal medicine, surgery and veterinary medicine); Ralph C. Croizer, Medicine, Modernization and Cultural Crisis in India and China, 12 Comp. Stud. Soc'y \& Hist. 275, 275-91 (1970). 
focal points of its current 5-year plan. An entire technology park in Houzhou has been devoted to the scientific study of Chinese medicine. Most of the investment occurs in state institutions. Much of the impetus arises from fears that foreign pharmaceuticals will dominate the Chinese market. ${ }^{65}$

Despite being driven by philosophies and theories, TCM's "traditional knowledge content is not easy to define." ${ }^{66}$ As TCM increasingly gets integrated with Western medicine, associated traditional and indigenous knowledge practices are sidelined as they become less of a priority. Indeed, recent legislative interventions in TCM in China do not address its traditional knowledge component in any specific way. ${ }^{67}$ Rather, individuals or corporations are positioned as recognized claimants to intellectual property rights in TCM.$^{68}$ Thus, one logical consequence of integration of TCM with Western scientific medical techniques is China's $\mathrm{cm}$ brace of patents as a viable protection regime for TCM.

Although there has been little regulation of TCM in China until fairly recently, the protection of TCM is not limited to the pursuit of its integration with Western scientific medicine. Rather, China sends a mixed signal reflecting, to a certain degree, a dialectical approach to intellectual property (patent) in the context of TCM. For example, the 1992 substantive law on the protection of Traditional Chinese Medicines ${ }^{69}$ places emphasis on research and development $(R \& D)$ of innovations in the field of TCM, and adopts language suggestive of a Westernstyle scientific standard of validation for TCM. ${ }^{70}$ Because "[t]he law is not applicable after patent rights have been applied for," the Chinese protection of TCM has been described as "a sui generis system designed to operate in conjunction with patents." "1 The law's focus on $R \& D$ appears to facilitate recent innovations on TCM as a prelude to their uptake into the conventional patent system, an important step in bolstering the integration of TCM into the Western scientific system.

65. Eiland, supra note 39 , at $78-79$.

66. Id. at 79 .

67. See China's Regulation on the Protection of Traditional Chinese Medicine (1992), http:// cq.netsh.com/bbs/751605/html/tree_5837217.html [hereinafter Regulation].

68. Eiland, supra note 39, at 77.

69. See Regulation, supra note 67.

70. For example, the regulation makes reference to the protection of "stable" forms of TCM which is suggestive of "scientific replicability." Regulation, supra note 67, art. 3. See also Eiland, supra note 39 , at 77.

71. Eiland, supra note 39 , at 77. 
From all indications, China's head start in the integration project of its TCM with Western scientific medicine, supported by its extraordinary human and techno-scientific resource base for the project, makes patenting an attractive option for that country's ultimate objective to protect its traditional medical knowledge and practices. China is a major player in the global economy, and a formidable competitor with little to fear and much to gain from bringing its rich TCM into the global market place. It would seem then that the concern about biopiracy does not have the same resonance in China as in India and the South East Asian countries, and in most of the developing world. In its global dispersal, transformations, and continued integration with conventional medicine, TCM is a showcase for cultural cosmopolitanism.

China's lack of enthusiasm about the establishment of a database for its TCM and its apparent favoring of a direct patent and so-called sui generis protection model is explained by a number of other reasons. First, the current level of protection of TCM under the patent regime, and advances in TCM's integration with conventional medicine, make the idea of a database fairly unattractive to China. ${ }^{72}$ Second, China, Korea, and Japan have a partially shared history regarding the development of traditional medicine. ${ }^{73}$ Thus, for the purpose of documentation, language may become a key obstacle. The same formula used for traditional medicine in each of these countries may be articulated via differentiated linguistic and philosophical expression and emphases. ${ }^{74}$ To this end, Eiland observes that:

It is difficult to communicate precise information about some aspects of TM given this level of uncertainty. The titles of TCM as expressed in Chinese characters have an ideographic meaning as distinct from a phonetic one as in an alphaberic system. When Chinese characters are translated into English directly - without explanation-a scientist would not understand their meaning. Many words indicate not only specific herbal materials and effectiveness but also expressions familiar only to Chinese culture. The problem is particularly acute with remedies involving multi-herb formulations. ${ }^{75}$

With regard to herbal formulations, CHM is a subset of TCM, and perhaps

72. Id. at 79 .

73. Id.

74. Id.

75. Id. 
the most prominent, given that herbs account for over 80 percent of TCM formulations and practices.$^{76}$ Along with other forms of CAM, CHM has gained much global popularity, and enjoys prominent visibility and patronage in the Western world." The U.S. Food and Drug Administration (FDA) has indicated its intention to recognize the marketing of botanicals as prescription drugs. ${ }^{78}$ This is already the case in a number of countries, including Japan and Germany. In addition to its acceptability in the centers of global financial capital in the West, the potential leap of herbal medicine from natural food products or naturaceuticals in the United States, to prescription drugs and other possibilities, continue to fuel the market for the botanical industry and CHMs from South Asia, especially Taiwan. ${ }^{79}$ In fact, Taiwan ranks third to Japan and Germany for R\&D, manufacturing, and quality control of herbal medicines. ${ }^{80}$

The Western scientific approach to phytomedicine (i.e., drug development based on herbs) involves, for the most part, the isolation or production from plants of bioactive compounds having new or known structures to serve as drugs or lead compounds for drugs. It also involves the use of bioactive agents from plants as pharmacological tools, and the use of an entire plant or part thereof as herbal medicine. Without a doubt, phytomedicine is a universal approach to drug discov-

76. The centrality of herbs in TCM is not a phenomenon peculiar to that system of medicine. Indeed, it seems to be the case with virtually all non-conventional medical traditions. See OcuAMANAM, supra note 14, at 118-26 (providing an analysis of the role of herbs in traditional medicine). See generally Medicinal Plants: Their Role in Health and Biodiversity (Timothy R. Thomlinson \& Olayiwola Akerele eds., 1998) [hereinafter Medicinal Plants] (a collection of articles discussing the role of medicinal plants).

77. In many developed countries, CAM is becoming more popular. For example, the percentage of the population that has used CAM (which includes TCM) at least once is 78 percent in France, 70 percent in Canada, 48 percent in Australia, 42 percent in the United States, and 38 percent in Belgium. See World Health Organization, Traditional Medicine Strategy 2002-2005 1-2 (2002). See also D.M. Eisenberg et al., Unconventional Medicine in the United States: Prevalence, Costs and Patterns of Use, 328 New ENG. J. Med. 246, 246-52 (1993); Edzard Ernst, Prevalence of Use of Complementary/Alternative Medicine: A Systematic Review, 78 Bull. of the World Health Org. 252, 252-57 (2000).

78. See U.S. Food and Drug Administration et al., Guidance for Industry Botanical Drug Products (2004), available at http://www.fda.gov/cder/Guidance/4592fnl.pdf; Dennis Normile, The New Face of Traditional Chinese Medicine, 299 Scr. Mac. 188, 188 (2003), available at www. sciencemag.org.

79. See Hsiao, supra note 25 , at 2.

80. Id. 
ery in virtually all cultures and civilizations, even though the methodology of discovery may vary in detail. ${ }^{81}$

For patenting purposes, the Western scientific approach to phytomedicine is readily privileged. As noted above, that approach concentrates on the isolation of core or single chemical compound(s) and their association with biological activities that are relevant to clinical application. More than this, it is able to purify the compounds or structurally modify or synthesize them so as to remove the resulting invention from the "realm of nature" and discovery into the patentable module. ${ }^{82}$ Under this practice, there is little mixing of herbs or plants and plant parts. For the most part, the combination or mixture involves known compounds. In contrast, CHM handles compounds that are not pure. Most of the inventions relate to plants, plant parts, and their diverse mixtures or combinations, resulting in complex formulations. ${ }^{83}$ Also, as already noted, CHM is theory-driven. Leading producers of herbal drugs, such as Japan and Germany, pursue a strictly scientific approach to herbal medicine; they strip it of any theoretical foundation and transform it into a context-neutral exercise.

For example, Japan's adaptation of TCM, the Kampo, which dates back to between the fifth and seventh centuries, owes its identity to the filtration or separation of underlying TCM theories. ${ }^{84}$ Japan is one the first countries in the world to take a strictly scientific approach to TCM, ridding it of its theories and pragmatically retaining the herbal knowledge in its scientific form. ${ }^{85}$ Following a checkered history

81. See Ogun manam supra note 14, at 118-26; Hubertus Cranz, Medical Plants and Phytomedicines within the European Community, in Medicinal Plants, supra note 76, at 194-95; Robert G. Pinco, The Evolving Status of Herbals and Phytomedicines in the United States, in Medicinal PLants, supra note 76 , at $198-204$.

82. See Agrawal,supra note 7, at 179; Chidi Oguamanam, The Convention on Biological Diversity and Intellectual Property Rights: The Challenge of Indigenous Knowledge, 7 S. Cross U. L. Rev. 89 (2003). See generally Yano, supra note 7 (discussing the longstanding prohibition in the U.S. patent case law against the patenting of "products of nature").

83. In other domains of CAM outside of the CHM module, complex cultural rituals or ceremonies, observations and practices are part of the traditional medicinal intervention. According to Native American scholars Batiste and Henderson, while the Western scientific model of intervention may understand the application of a native herb, it may not produce a curative outcome without the accompanying ceremony, ritual songs or chant, and prayers. See Marie Battiste \& J. (SA'K'Ej) Youngbloon Henderson, Protecting Indigenous Knowledge and Heritage: A Global Challenge 43 (2000).

84. See Katsutoshi Terasawa, Evidence-Based Reconstruction of Kampo Medicine: Part I-Is Kampo CAM?, in Evidence Based Complementary and Alternative Medicine 11, 13-16 (2004), available at http://ecam.oxfordjournals.org/cgi/reprint/1/1/11.

85. Id. at 14 (noting that the "Japanese paradigm of Kampo is little dependent on, if not free from, the Yin-Yang/Five Elements paradigm [of TCM] ... [and] can be characterized as a simplified, positivistic and pragmatic version of Chinese herbal medicine"). 
that parallels historic transformations in Japanese society, Kampo medicine has been fully entrenched in the curriculum of Japanese medical and pharmaceutical education and in its health care delivery. In this regard, Katsutoshi Terasawa notes "[a]fter their official recognition as medical drugs, chemical and pharmacological research on Kampo herbs has made dramatic progress in Japan. The chemical components of each herb are now analyzed in such detail that I think we can now safely talk about the new science of Kampo as the science of complex, or compound drug." ${ }^{86}$ According to Hsiao, "more than $70 \%$ of the doctors in Japan who were trained under the Western medical system prescribe Kampo extraction. Kampo extractions in Japan were studied scientifically for their single compound as well as for the safety and efficacy of [their] formulas. ${ }^{87}$

The success of Japan and Germany as leading global suppliers of herbal and botanical drugs can be attributed, at least partially, to their strict scientific approach to the manufacturing process. ${ }^{88}$ The "success model indicates the acceptance of Western drug-like herbal medicines in the main pharmaceutical markets today. ${ }^{*}$ One other reason for this success is that the scientific approach easily makes herbal medicine amenable to patent protection. Consequently, the scientific approach assures herbal medicine's acceptability and legitimacy. Its global acceptability becomes a source of economic empowerment for those countries that follow the scientific model. For countries such as Japan and to some extent, China, one way to address the logjam arising from the failure of the patent system to accommodate traditional medicine and the resultant marginalization of non-Western knowledge forms is to strip herbal medicine of its local knowledge and theoretical content. That way, its complete integration with, or uptake by, Western scientific medicine becomes fait accompli. ${ }^{90}$ Because it does not focus on the local knowledge content of herbal medicinal and associated theories, this ap-

86. Id. at $15-16$.

87. Hsiao, supra note 25, at 6 (citations omitted). But see Terasawa, supra note 84, at 13 (proposing that the effects of Kampo medicines fall into a "multiple-interacting components paradigm").

88. The Japanese medical tradition has a historical relationship with the Durch system. Yamawaki, one of the leading Kampo physicians, was a critic of the Chinese understanding of human anatomy. His significant influence assured a unique identity for Kampo. His time marked an important period that emboldened Japanese physicians to introduce Western medicine "through the Dutch, who were the only Westerners officially permitted to trade with Japan." See Terasawa, supra note 84 , at 14 .

89. Hsiao, supra note 25 , at 6 .

90. Terasawa, supra note 84 , at 13 (noting that Kampo medicine's complacency with being a local standard should not be tolerated: "Kampo should not and cannot avoid meeting the challenge of the evidence-based medicine of the West"). 
proach does not problematize or magnify the troubled relationship between the conventional patent system and indigenous or local knowledge.

By deliberately positioning its traditional medicinal practices in Western scientific ontology, China's commitment to the protection of TCM, including CHM, via the conventional patent system is unequivocal. When TCM is supported and empowered through the interaction of the scientific and legal frameworks, it is then easy to analogize it to Western biomedicine. Under this approach, it is diffcult for the advocates of TCM to problematize intellectual property as is the trend by other proponents of local knowledge.

Unlike the marked shift in Japanese Kampo rendition, China strictly holds on to the theoretical and philosophical orientation of its medical traditions, which is located within the broader CAM. In practice and as a process, the latter is an epistemological alternative to Western biomedicine. Thus, in regard to the protection of its TCM, China maintains a dialectical and simultaneously ambivalent relationship with the patent system. It sends a mixed signal by aggressively entrenching TCM into the Western scientific medical ontology and conventional intellectual property system while, at the same time, capitalizing on TCM's deep theoretical roots as an alternative to Western biomedicine. The divide between $\mathrm{CHM}$ and Western scientific medicine has been abridged differently in Taiwan, through creative regulatory intervention.

\section{B. Taiwan: Creative Legal Intervention}

Recent developments in Taiwan show a willingness to consolidate or improve its status as the world's third largest producer of herbal medicine. Like Japan, Taiwan is sure-footed in a strict scientific approach to $\mathrm{CHM}$. However, Taiwan realizes that although that approach makes for successful patent applications, it does not accommodate the theoretical and traditional knowledge content of TCM. Taiwan seeks a revision of its patent regime to accommodate a theoretical approach to TCM and to recognize TCM's emphasis on the combination of complex plant formulations as opposed to the focus of Western scientific methods on single or core chemical compounds as constituting the raw compounds for producing herbal drugs. In 2002, Taiwan proposed a Draft CHM Invention Patent Guideline, which aims to plug the loopholes in its extant patent law, in view of the difficulties associated with the patentability of $\mathrm{CHM}$ in its theoretical coloration."

91. See generally Draft Guideline, supra note 63 . The debate continues regarding its finalization and adoption. 
Perhaps the most significant aspect of CHM theory is that it represents an alternative epistemic approach to that which underlies Western scientific medical knowledge and understanding. ${ }^{2} \mathrm{CHM}$ has been described as the "crystallization of Chinese people's wisdom and experience. ${ }^{193}$ This collective knowledge pool has a bearing on the way herbs are used for drugs, and on overall therapeutic intervention in health service delivery. The components of, and insights into, the operational mechanism of the Chinese medical tradition are informed by specific elements of its theoretical construct. This construct includes concepts such as $Q i$, Ying-Yang, and Meridian, as well as the process of prescription of herbal formulas, the practice of acupuncture, moxibustion, etc. ${ }^{94}$

As mentioned earlier, Western scientific medicine adopts Cartesian reductionism, separating the body and the mind..$^{95}$ It also adopts a targeted approach to therapeutic intervention. In terms of the use of herbs for drug production (phytomedicine), this model concentrates on isolating single or core chemical compounds from plants. Western medicine adopts a corresponding therapeutic intervention that aims to "identify a particular chemical, hormonal or biological imbalance and to treat the symptom with a counteracting medicine (normally a bioactive compound directed to a well-defined disease [and organ] target). ${ }^{.96}$ In contrast, CHM, like other non-conventional or traditional medicinal systems, adopts a holistic approach that encapsulates Chinese philosophical worldview and reflects the nature of human interaction with natural forces. ${ }^{97}$

In a nutshell, a successful therapeutic intervention via $\mathrm{CHM}$ results from the attainment of equilibrium or balance in the human body. This is depicted as Ying and Yang, which correspond to parts of the body (substance of body cells and chemicals) and the energy or forces that activate the body cells. The major raw materials for CHM are plants, and to some degree animals and minerals. CHM involves the characterization of various properties of different plants under four drug essences,

92. See Oguamanam, supra note 14 , at 121-22.

93. See Pei, supra note 61 , at 68.

94. See Oguamanam, supra note 14, at 102-103; Barbara Avery \& Rocky Avery, Oriental Healing: The Ying-Yang Concept, in Folk Medicine and Herbal Healing 139, 139-65 (George G. Meyer et al. eds., 1981); Pei, supra note 61, at 68.

95. See Hsiao, supra note 25 , at 4.

96. Id. See also Oguamanam, supra note 26, at 96-97.

97. Hsiao, supra note 25, at 4. But see David Phillips, Health and Health Care in the Third WorLd 80-83 (D.J. Dwyer ed., 1990) (arguing that the holistic construct of traditional medicine may be overstretched, does not necessarily hold true in all cases, and could create a misleading impression of traditional medicine's efficiency and limits). 
namely, cold/cool drugs for tackling Yang, and warm/hot drugs for Ying diseases. ${ }^{98}$ In addition to these four essences, CHM's theoretical outlook includes five flavors, ${ }^{99}$ four directions, ${ }^{100}$ and seven effects. ${ }^{101}$ In terms of prescription or delivery, CHM is administered in two formulations, either as single applications comprising one herbal preparation (Dan Xing) for the treatment of acute conditions, or a complex combination or mixture of various herbs ( $F u F a n g$ ) for treating chronic diseases. Because of its focus on one herbal preparation, Dan Xing is closer to Western scientific medicine than $F u$ Fang, which enjoys greater preeminence in CHM.

Taiwan's new and pending initiative for the calibration of its patent regime to accommodate TCM tackles the subsuming of $F u$ Fang under the extant patent system. Because of the patent regime's focus on a strict scientific approach to herbal medicine and the recognition of single or core active substances with therapeutic consequences, herbal drug development in Taiwan under TCM is, for the most part, limited to Dan Xing. ${ }^{102}$

The diagnostic process that precedes the administration of $\mathrm{CHM}$ involves the identification of a patient's Zeng, or biochemical profile or data, through a number of strategies, including "observation, listening, questioning and palpation according to TCM theory." ${ }^{103}$ Identification of Zeng is followed by:

prescription of herbal formulas [which] use TCM theory to balance the different effects of the plants, eliminate toxicity and enhance efficacy. This is the process by which herbal formulas can achieve their effects as recorded in the classics; the pharmacological effects and the harmless combination of herbs are through the correct application of TCM theory and not because natural products are indeed safe and non-toxic. ${ }^{104}$

TCM's emphasis on a complex combination and interaction of various herbs and underlying theories that gird their prescription and use make the identification of active ingredients in plants not only difficult but also of trivial essence. At

98. See Hsiao, supra note 25, at 5. See generally Barbara Avery \& Rock Avery, supra note 94, at 139-65.

99. Pungent, sour, sweet, bitter, and salty. Hsiao, supra note 25 , at 5.

100. Ascending, floating, descending, and sinking. Id.

101. Single, additive, synergic, antagonistic, inhibitive, destructive and opposite. Id.

102. See Id.

103. Id.

104. Id. 
the same time, the combination of herbs and their interactions are yet to receive any serious consideration in Western scientific approaches to herbal medicine, ${ }^{105}$ nor are they accounted for by the conventional patent system. Key aspects of TCM's challenge to the patent regime, which the 2002 Taiwan Draft CHM Invention Patent Guidelines propose to tackle, ${ }^{106}$ include:

(a) Confusion in the naming of plants in the different TCM classics, which tends to become problematic for patent purposes when a CHM invention does not involve a pure compound. In this case, the Draft prescribes different approaches to be followed to achieve taxonomic uniformity and to mitigate inconsistency in the classical nomenclature. ${ }^{107}$

(b) The difficulty with identifying active ingredients in crude materials used in TCM for the purpose of TCM patent examination. The Draft makes a bold attempt to recognize the differences in plant characteristics due to the environments of their cultivation or the circumstances of their harvest. It also provides for accommodation of information in a TCM patent specification dealing with the therapeutic functions of different parts of the same plant where applicable. ${ }^{108}$

(c) The nature of plants and plant varieties as living organisms which, of necessity, have variable characteristics, in contrast to chemical compounds which can be reproduced at an industrial scale of uniformity and stability. To this end, the Draft further recognizes four types of $\mathrm{CHM}$ patents. The first is combination preparation, referring to a combination of plants or parts thereof. Thus, in place of identification of active ingredients, identification of the plants used in the combination will suffice. Perhaps most importantly, a CHM patent based on a combination preparation that cannot be listed by chemical composition can be defined via product-by-process, while limiting the patent claim to only the product. ${ }^{109}$ The second type is patents based on

105. Id. (stating that it is a popular, but false belief that CHM a re medicines solely for chronic and minor diseases). See also Terasawa, supra note 84 , at 13 (stating that the linear cause-effect approach to chemical remedies, which is the hallmark of Western medicine, "is now being chatlenged, even within the realms of Western science").

106. The original or official language of the Draft Guideline is Mandarin. Page references to the Draft Guideline appear as they appear in the original document. Due to the absence of an official English translation, this section draws from Hsiao's elaboration of the Draft Guideline. See Hsiao, supra note 25 , at 14-15 (identifying the critical issues addressed by the Draft Guideline).

107. See Draft Guideline, supra note 63, at 28-29; Hsiao, supra note 25, at 14.

108. Id.

109. For a detailed analysis of the four categories of $\mathrm{CHM}$ product patents, see Hsiao, supra note 25 , at 14 . 
CHM extracts and purified plant parts. Here, it suffices if only the principal active ingredients are identified and not necessarily each individual active ingredient. Again, where the active ingredients cannot be listed or represented by chemical names and structures, they can be defined by way of product-byprocess. ${ }^{110}$ The third CHM patent type is the CHM Active Compound, which applies where the compounds extracted from plants have been successfully purified. This fits within the Western scientific standard for phytomedicinal drug discovery. "I The last type is the CHM Delivery System which relates to $\mathrm{CHM}$ administration, dosage, etc. This category provides perhaps the most proactive uptake of CHM theory under the proposed patent system in Taiwan. ${ }^{112}$ It specifically requires patent specifications to include information on the treatment of Zeng, the raw materials applied, as well as the TCM theory deployed in establishing the efficacy of the invention. Where an invention targets a disease outside TCM ("Western disease"), it must be scrutinized for efficacy under Western pharmacology. ${ }^{113}$

(d) The prevalence of impure substances in plants and the problem associated with establishing CHM's pharmacological efficacy. The Draft provides for difficult cases where an extract from a part of a particular plant might have a different medicinal value from the one already associated with the main plant in the treatment of a Zeng. A person having ordinary skill in the art (PHOSITA) cannot associate this with codified TCM. As a way out, the Draft provides for the inventor to specifically prove or disclose the efficacy of this CHM invention or to supply references in the specification to buttress the invention's efficacy. Again if the TCM invention targets a disease not known to TCM ("Western disease"), its efficacy will require Western pharmacological scrutiny. ${ }^{114}$

Although the Draft TCM Invention Patent Guideline is still being debated and is yet to come into force, the initiative is significant in a number of respects. First, it is symbolic of the legal creativity required of developing countries to demonstrate that the Agreement on Trade-Related Aspects of Intellectual Property Rights (TRIPS) did not completely obliterate the status of intellectual property as subjectmatter of national law. However, if and when the Draft is adopted, there may be a

110. Id.

111. Id.

112. See Draft Guideline, supra note 63, at 32-39; Hsiao, supra note 25, at 15.

113. Hsiao, supra note 25 , at 15.

114. Id. 
reasonable basis to challenge it on grounds of lack of compatibility with TRIPS."15 Second, the Taiwanese initiative exposes subtle but significant differences in the priorities of developing countries in regard to securing their individual interests under the patent system. Indeed, these differences drive country-specific strategies for engaging with the intellectual property system. Third, Taiwan's initiative represents the first time any country has proffered a legal remedy for the epistemic schism between traditional medicine and Western scientific medicine via the patent system. ${ }^{116}$ Fourth, the initiative is indicative of the potential for the co-existence of traditional and Western scientific medicine, albeit in the context of drug development and, to some extent, therapeutic intervention under a single intellectual property framework. Thus, the initiative has a potentially positive implication for the institutionalization of medical pluralism in the long run.

Fifth, and perhaps most important, the integration of TCM in its theoretical construct with its strict atheoretical or Western scientific transformation under one legal framework is a powerful representation of the reality of cultural cosmopolitanism. Not only docs the Draft affirm the epistemic identities of Western scientific medicine and CHM, it also acknowledges the reality of their interaction and melding. Sixth, in relation to the Indian-championed documentation of traditional medicinal knowledge, Taiwan's TCM Invention Patent Guideline is a more direct attempt to introduce the theoretical core of traditional medicine (CHM) into the intellectual property (patent) system with which its has continued to have a frosty relationship. Seventh, Taiwan's proposal for the accommodation of the theoretical essence of $\mathrm{CHM}$ in its patent system is significant for many indigenous and local communities and, certainly, the rest of the developing countries. The latter's current efforts concentrate on an anti-appropriation strategy which they seek to implement against biopiracy. The anti-appropriation strategy is symbolized in the TKDL project, which essentially constitutes a means to an end and, arguably, in some way, the end itself. The more desirable end appears to be the empowerment of indigenous and local knowledge under the extant or new legal framework. Taiwan's initiative indicates this objective can be explored via an inward looking, cost-effective creative

115. It is merely within the realm of conjecture whether the Draft Guideline constitutes a technology-specific discrimination, which the TRIPS Agreement does not sanction. My preliminary understanding is that this Draft Guideline is compatible with TRIPS to the extent that it opens traditional medicine up to patentability-a development that is consistent with the spirit and letter of TRIPS in regard to bringing all technologies under the realm of patent protection. Indeed, since TRIPS is a foundation without a ceiling, counterintuitively, this initiative is a form of "TRIPS-plus."

116. See generally Oguamanam, supra note 26 (reviewing the patent-empowered epistemic schism that thwarts the protection of traditional medicine in international law and public health policy). 
strategy which potentially has ramifications for the rest of the developing world. It is instructive that Taiwan's strategy is being pursued via a patent examination guideline and not by means of a brand new piece of patent legislation. ${ }^{17}$

In sum, the Taiwanese initiative demonstrates that TRIPS did not completely obliterate the national character of intellectual property lawmaking. It shows that through creative legal interventions, states can devise intellectual property strategies that cater to their national experience and uphold their aspirations for rethinking the conceptual framework of the patent system in regard to traditional knowledge.

\section{Disclosure of Origins and Geographical Indications}

The third major development in the attempt to bridge the gap between the conventional patent system and traditional knowledge is disclosure of origins (DRs) and geographical indications (GIs). ${ }^{118}$ This last category does not directly apply to traditional medicine per se. In comparison to the first two examples, the significance of DRs and Gls is perhaps marginal, both in terms of their approach and impact on mitigating the patent system's disdain for traditional knowledge. Nonetheless, recent steam around DRs and GIs lends credence to the thesis of cultural cosmopolitanism. DRs and GIs reflect the interconnectedness and interdependence of knowledge systems and the global reach and exchange of locally susceptible cultural products. DRs and GIs add pressure to the intellectual property system at national and global levels for creative re-examination of the patent system's conceptual framework in terms of having to accommodate traditional knowledge.

\section{A. Disclosure of Origins}

Like the traditional knowledge database, DRs are an anti-appropriation strategy which could ensure some accountability in the use of traditional knowledge in

117. Taiwan's resort to the Draft Guideline is cost-effective. It also underscores the significance of subsidiary rules and regulations to the administration of intellectual property rights. Often, there is a significant disparity between the substantive provisions of a patent statute and its associated guidelines. In terms of patents, like all things, the devil resides in the details and these are usually elaborated in the guidelines.

118. For a general review of the concept of DRs and GIs, see Emanuela Arezzo, Struggling Around the Natural Divide: The Protection of Tangible and Intangible Indigenous Property, 25 CA Rdozo ARTs \& ENr. L.J. 367 (2007); Irene Calboli, Expanding the Protection of Geographical Indications of Origin Under TRIPS: Old Debate or New Opportunity?, 10 Marq. INtell. Prop. L. Rev. 181 (2006); S.K. Soam, Analysis of Prospective Geographical Indications in India, 8 J. World INtell. Prop. 679 (2005), available at http://www.blackwell-synergy.com/doi/pdf/10.1111/j.1747-1796.2005.tb00274.x. 
patent applications. In addition, DRs, which derive their impetus principally from the 2000 Bonn Guidelines on Access to Genetic Resources and Fair and Equitable Sharing of the Benefits Arising out of their Utilization, ${ }^{119}$ are a non-mandatory strategy aimed at enhancing the determination of prior art and the facilitation of efficient monitoring of prior informed consent (PIC) and access and benefit sharing (ABS), especially as elaborated under the Convention on Biological Diversity (CBD). ${ }^{120}$ Subject to variation in detail, under DRs, patent applications for inventions relating to genetic resources are required to disclose the "sources" or "origin" of the genetic material and/or associated traditional knowledge. Because plant and animal materials form a significant aspect of traditional medicine, the limitation of DRs to patent applications involving genetic resources directly draws attention to the nexus between traditional medicine and the patent system.

Strong opposition and skepticism have trailed DRs, the exploration of which, though desirable, is outside the framework and scope of this article. Opposition is grounded in a number of reasons, including non-feasibility, cost and effectiveness of monitoring the origins and uses of genetic resources, and the technical distinction between "source" and "origin." 21 A nother objection relates to the nature of traditional knowledge and the difficulties associated with determining its application with any accuracy in the patent context. Then, reservation attaches to the identification of the origin of both genetic resources and associated traditional knowledge, especially where there is a disagreement in regard to the details and application of such knowledge between original and subsequent claimants. Also of concern is the appropriateness of using the patent system, which is primarily designed to advance innovation, and to mitigate concerns about equity and benefit sharing. ${ }^{122}$ Related to this are fears of uncertainty and the potential of a DR requirement to "overload" an already troubled patent system by further complicat-

119. The Draft Guideline was approved pursuant to Decision VI/24 of the 2002 Conference of Parties (COP) Meeting of the CBD, available at http://cbd.int/decisions/default.asp? $\mathrm{m}=\mathrm{COP}$ $06 \& \mathrm{id}=7198 \& \lg =0>$.

120. Convention on Biological Diversity, June 5, 1992, 31 I.L.M. 818.

121. There is no strict correlation between the traditional origin of a particular genetic material and its present source even though the undergirding knowledge and application may be the same. As an example, over time, second comers may sponsor the cultivation of a genetic resource ex situ, creating a more viable source for it which is different from its historic or traditional origin. Also, migration patterns, ecological dynamics and other environmental factors can fuel disparity between the origin and subsequent source of genetic material.

122. For a critical appraisal of the DRs, see Alison Hoare \& Richard Tarasofsky, Asking and Telling: Can Disclosure of Origin Requirements in Patent Applications Make a Difference?, $10 \mathrm{~J}$. Wor LD Intell. Prop. 149 (2007). 
ing the question of patentability. ${ }^{123}$ Lastly, the politics of DRs is fast becoming complicated: it began by pitting transnational corporate interests in the developed world against rural communities and developing countries. Now, as Alison Hoare and Richard Tarasofsky note, the "burgeoning biotechnology industry in many developing and biodiverse countries... [means] the lines between provider and user countries are becoming increasingly blurred, and the debates [on DRs] ... are more nuanced than is of ten suggested."124

Despite the reservations about DRs, in the less than ten years since disclosure of origin entered the policy discourse on the intersection of traditional knowledge, intellectual property, and access and benefit sharing, it has in some cases become entrenched as part of national law. Certainly, DRs are an important subject in the ongoing policy discussions in key international forums, including the CBD, WIPO Intergovernmental Committee on Genetic Resources, Traditional Knowledge and Folklore (IGC), World Trade Organization (WTO), and regional trade and intellectual property organizations. ${ }^{125}$ For instance, following the 1998 European Commission (EC) Biotechnology Directive, ${ }^{126}$ a number of European Union countries enacted national laws that incorporate DRs. ${ }^{127}$ Notwithstanding variations in the details of country-specific regimes on DRs in these European countries, provisions of the legislation highlight tacit acknowledgement of gaps in the conventional patent system, ${ }^{128}$ the imperative for transparency, and the need to restore the integrity of that system. In addition to national initiatives in Europe, the incorporation of DRs into multilateral intellectual property administrative and regulatory cooperatives, such as the Patent Cooperation Treaty (PCT) and the Patent Law Treaty (PLT), is currently being elaborated in these forums. ${ }^{129}$ In developing countries, regional bodies such as the Andean Pact, the African Union, and the Pacific Forum have,

123. Id. at 150 . See also A rezzo, supra note 118 , at 387.

124. Hoare \& Tarasofsky, supra note 122, at 159.

125. For a detailed elaboration of the debates about DRs, see A rezzo, supra note 118, at 393-98.

126. See Council Directive 98/44/EC, 27, 1998 O.J. (L.213) 13, 15 (EC).

127. For example, Belgium, Denmark, Germany, and Sweden. Also Norway and Switzerland have reached advanced stages in the introduction of DR provisions in their patent regimes.

128. It needs mentioning that fair access and equitable benefit, as well as regard for the use of traditional knowledge in an invention, did not motivate the introduction of DR regimes in the European countries. See Hoare \& Tarasofsky, supra note 122, at 154. Further, in these countries, DRs are either optional, or when they are required, there is no sanction attached to non-disclosure. Nonetheless, DR provisions assist in tracing its use and in the determination of prior art.

129. See Arezzo, supra note 118 , at 380-82. 
since the early 2000s, adopted common legislative frameworks supportive of PIC, ABS, and DRs among their member states. ${ }^{130}$

In addition to regional initiatives, developments are taking place at the national level. Many developing countries have adopted or amended laws to provide for divergent national regimes incorporating PIC, ABS, and DR requirements. Examples of those countries include Brazil, Costa Rica, Egypt, India, the Philippines, and Venezuela. ${ }^{131}$ These countries, especially Brazil, India, and Venezuela, along with Thailand, Cuba, and others, support amending the patent provisions of the TRIPS Agreement to accommodate DRs. They also endorse the creation of a sanction and enforcement regime akin or pursuant to the WTO dispute settlement and enforcement mechanisms for non-compliance with DRs. ${ }^{132}$

From this parsimonious overview, it is obvious that the scope of implementation and ongoing discussion regarding DRs are quite widespread across relevant national, international, and regional patent forums. Despite reservations about the long-term feasibility of DRs, there is little doubt, thus far, that proponents of the concept are able to elicit a response in the conventional patent system that is open to grappling with the reality of traditional knowledge. Like the results of the TKDL project explored in Part I, this shift marks a significant departure from helpless reliance on the traditional excuse that intellectual property rights are hopelessly irreconcilable with traditional knowledge.

Without a doubt, for holders of traditional knowledge, DRs, like the digital library project, are not necessarily or conclusively an end in themselves. They are a site for negotiating some form of temporary compromise between the patent system and traditional knowledge. Perhaps the importance of DRs lies more in their potential to open up the patent system to the demands of traditional knowl-

130. The 1996 Andean Pact (Bolivia, Colombia, Ecuador and Peru), Decision 391 on Common Regime on Access to Genetic Resources was the precursor to the 2002 Decision 486 which directly provides for DRs. The African Model Legislation for the Protection of the Rights of Local Communities, Farmers and Breeders and Regulation of Access to Biological Resources-an initiative that started in 1997 and was formally adopted in 2000 by the African Union, among other things, aims at proving a framework for access to Africa's rich biological resources, associated traditional knowledge in accordance the principles of PIC and ABS which provide a compelling basis for national DRs regimes. See Grain, Biodiversity Rights Legislation (BRL), Nov. 17, 2007, http://www.grain.org/brl/.

131. See Hoare \& Tarasofsky, supra note 122, at 156. See also Arezzo, supra note 118, at 382. See generally Grain, supra note 130 (containing a database of "biodiversity rights legislation" which "is a collection of emerging laws that directly affect people's control over agricultural biodiversity in developing countries. It compiles those legislative texts that define rights in relation to genetic resources or to the knowledge associated with those materials. They may be rights of ownership, intellectual property, stewardship, access, sovereignty or something else").

132. Arezzo, supra note 118 , at 382-83. 
edge for recognition in its own right, and the urgent need for a meaningful engagement between traditional knowledge and the patent system, than with the feasibility of DRs as a long-term solution. The acceptability of DRs in developing countries reflects the dialectics that characterize those countries' response to intellectual property, especially in the context of its application to traditional knowledge. Despite their characteristic suspicion and ambivalent attitude regarding intellectual property, they find DRs to be one means by which to address aspects of their concerns. Finally, the willingness of developed and developing countries to consider DRs tacitly affirms the reality of cultural cosmopolitanism and the melding of information across knowledge systems, a phenomenon that is well reflected in most patents involving genetic resources. This is true particularly in light of traditional medicines' dependence on plant and animal genetic resources. In a sense, that dependence has some correlation with the restriction of DRs to patents dealing with the use of genetic resources and associated traditional knowledge. Next, we examine the place of GIs in this matrix.

\section{B. Geographical Indications}

Similar to DRs, GIs provide an important, albeit inadequate, site for giving some balance to the TRIPS Agreement and the WTO process in regard to cultural knowledge and products originating from developing countries. ${ }^{133}$ Unlike DRs, GIs are accommodated under the TRIPS Agreement. ${ }^{134}$ According to Article 22 (1) of TRIPS, GIs are "indications which identify a good as originating in the territory of a Member ... where a given quality, reputation or other characteristic of the good is essentially attributable to its geographical origin." 135 Simply stated, a GI is a trademark-like form of protection of the integrity, specialty, and commercial value of products whose uniqueness is incidental to their geographical origin and customary process of manufacture. ${ }^{136}$ The recognition of GIs in the international intellectual

133. See Michael Blakeney, Proposals for the International Regulation of Geographical Indications, 4 J. World Intell. Prop. 629, 646-52 (2001); Calboli, supra note 118, at 200; José Manuel Cortés Martín, TRIPS Agreement: Toward a Better Protection for Geographical Indications?, 30 Brook. J. INT'L L. 117, 175-83 (2004); Soam, supra note 118, at 679-82; Sunder, supra note 4, at 297.

134. In comparison to other pre-TRIPS regimes on GIs, TRIPS elaborates an ambitious provision on GI that characterizes that regime as "a true milestone in this respect." Calboli, supra note 118 , at 190 .

135. See also Articles 23 and 24 of TRIPS for additional provisions on GIs.

136. See Calboli, supra note 118, at 184 (exploring different definitions of GI and proffering her own definition as "names that identify agricultural or other products as originating from the specific geographical regions in which these products are grown and manufactured, and from which 
property regime predates the TRIPS Agreement, reflecting the strong historic and ongoing support for GIs in Europe..$^{137}$ Given TRIPS' disregard for indigenous or local knowledge, its provisions on GIs assume heightened significance. Notably, they have become a vent for channeling the desires of indigenous and local communities to remedy the inadequacies of the TRIPS Agreement in specific regard to the recognition and protection of their cultural and agricultural products. ${ }^{138}$

However, developing countries are caught at the crossroads of the regional power play between Europe and the United States over GIs. ${ }^{139}$ This tension has stalled the expansion of the scope of protection for GIs beyond wines and spirits, and the establishment of an international registry for GIs pursuant to TRIPS. ${ }^{140}$

they derive their qualities and reputation"). See also WIPO, About Geographical Indications, http:// www.wipo.int/geo_indications/en/about.html (last visited July 12, 2008) (explaining that Gl is "a sign used on goods that have a specific geographical origin and possess qualities, reputation or characteristics that are essentially attributable to that place of origin. Most commonly, a geographical indication includes the name of the place of origin of the goods. Agricultural products typically have qualities that derive from their place of production and are influenced by specific local factors, such as climate and soil. Whether a sign functions as a geographical indication is a matter of national law and consumer perception."). For further definitional insights on GI and its metamorphoses, see Calboli, supra note 118, at 184 \& nn. 14-16 (citing Felix Addor \& Alexandria Grazioli, Geographical Indications Beyond Wines and Spirits: A Roadmap for a Better Protection for Geographical Indications in the WTO/TRIPS, 5 J. World In tell. Prop. 865, 867-69 (2002)).

137. For a concise account of the European-championed evolution of the protection of Gls in their diverse designations under various international instruments pre-TRIPs (i.e. the Paris Convention for the Protection of Industrial Property, the Madrid Agreement for the Repression of False and Deceptive Indications of Source on Goods and the Lisbon Agreement for the Protection of Appellations of Origin and their International Registration), their partial successes, failures and limitations, as well as the TRIPS framework for GIs, see Calboli, supra note 118, at 187-97. See generally Lee Bendekgey \& Caroline H. Head, International Protection of Appellations of Origin and Other Geographical Indications, 82 TMR 765 (1992) (noting that longer established industrialized nations in Europe and the former Soviet Union have a vested interest in establishing origin specific brand recognition).

138. See generally Ralph S. Brown, New Wine in Old Bottles: The Protection of France's Wine Classification System Beyond Its Borders, 12 B.U. INT'L L.J. 471 (1994) (noting with dismay the inadequate protection given to premium wines and wine regions in the United States and elsewhere). See also Calboli, supra note 118, at 197; Martín, supra note 133, at 175; Sunder, supra note 4, at 298-303.

139. Simply stated, America's reservation over strong GIs is that it undermines the use of names that have now acquired generic status, and that forcing countries to abandon such names would be very difficult and costly. Also, the United States fears that a strong GI will benefit European countries that have had pre-existing national legal regimes for GI protection in comparison to America and the developing countries who are latecomers to the GI concept. For an outline of arguments for and against minimalist and maximalist GI protection, see Calboli, supra note 118, at 142-64.

140. Article 23 requires member states to enact national laws to protect GIs in specific regard to wines and spirits even if such protection constitutes unfair competition, which is prohibited under Article 10 bis of the Paris Convention. Also, it clearly privileges GIs over trademarks that contain 
The attractiveness of GIs may outweigh the opposition to it, as illustrated by the record growth of Australia's wine industry, which has turned that country into a GI convert. ${ }^{1+1}$ In addition, a coalescing of developing countries and European interests in strong protection of GIs continues to strengthen global interest in GIs. ${ }^{142}$ Meanwhile, key opponents of GIs, such as the United States, have not yet fully explored TRIPS built-in exemptions ${ }^{143}$ to GIs that encapsulate a European compromise to limit GI protection, a concession that may well facilitate a diplomatic reprieve ${ }^{1+4}$ for the GI logjam. Apparently, this is what is required for developing countries and other stakeholders to take advantage of the potential which TRIPS has created for GIs.

Despite France's longstanding influence in TRIPS negotiations on GIs with the aim to protect its wines and champagnes, GIs are increasingly becoming an important asset for developing countries in the projection and protection of their unique cultural products in an increasingly globalized marketplace. For some, GIs represent a unique meeting point for CBD's proactive program for protection of biodiversity and local knowledge, and the WTO's trade regime in the interface between environment, trade, and development. Writing in reference to India's GI regime, which is strikingly popular among that country's local and poor communities, Sunder notes that:

GI relating to wines and spirits. Article 23(4) provides for post-TRIPS negotiations for setting up a multilaterally harmonized system for notification and registration of GIs in regard to wines and spirits. Article 24, inter alia, generally provides for further negotiations around GI at the TRIPS Council. Attempts to revisit GIs at that Council from the 2001 Doha Rounds of multilateral trade negotiations (development rounds) and the Cancun Summit in Mexico, has not resulted in any significant progress. See Calboli, supra note 118, at 194 (citing Martín, supra note 133, at 141-42).

141. See generally Calboli, supra note 118 (noting that following Australia's 1994 bilateral agreement with the European Union, that country dropped the use of French regions such as Burgundy or Chablis to describe its wines. The decision resulted in the birth of an authentic Australian wine industry which relies on Australia's regional names. Consequently, in 2003, Australia marked the first time its wines outsold French wines in both Britain and the United States).

142. See Calboli, supra note 118, at 195 (noting that in the last ten years Europe has continued to promote maximalist protection for GIs while the United States, Canada, and Australia remain opposed, and that "interestingly developing countries have increasingly taken sides with the European Union").

143. Notable exemptions are provided under the grandfather clause in Article 24(4), (5), which saves GIs used for some length of time before TRIPS, the use of GI in a Member country in good faith, and trademarks containing or consisting of GIs but used in good faith pre-TRIPS or before the protection of associated GI in a Member country. Finally, Article 46(6) saves the use of GIs that have acquired status as generic names.

144. See generally Calboli, supra note 118 (outlining "old" world efforts to ensure continued expansion of protection for GIs). 
[T] he turn to intellectual property for the poor is not simply another instance of a misguided "if value, then right" mentality ... poor people's turn to property is surely about economics, but is about social and cultural values as well. These claims recognize that the relationship between intellectual property and development goes beyond GDP. People, rich and poor alike, want recognition of their creativity and contributions to science and culture. ${ }^{145}$

From Native Americans in the United States, Canadian First Nations, and several aboriginal communities in Australia and elsewhere, to indigenous or traditional communities in Mexico, India, Ethiopia, and most of the developing countries, GIs have potential and real significance for the economic empowerment of local communities, their unique art works, and their ecologically endemic range of traditional or cultural products including coffee, ${ }^{146}$ tea, fruits, food crops, and other agricultural products. ${ }^{177}$ Pending negotiations on the expansion of GI

145. Sunder, supra note 4, at 301 (footnotes omitted). See generally Soam, supra note 118 (for a detailed analysis of the significance and prospects of India's new GIs regime, which came into effect in 2003).

146. The Ethiopian government's proactive role in reclaiming and branding three types of Ethiopian grown coffee after the three regions where they are grown, is an example of the growing developing country interest in trademark-like rights for their geographically sensitive products. (This appears to be a stop-gap measure in place of botched negotiations on the extension of TRIPS protection to Gls beyond wines and spirits pursuant to Article 24). The names are Yirgacheffe, Harrar, and Sidamo, which also correspond to the country's highly reputed coffee growing regions. Ethiopia prevailed over opposition from Starbucks to register these names globally as trademarks in Europe, the United States, Canada, Japan and elsewhere. Interestingly, Starbucks had to abandon its earlier attempt to register Sidamo as a coffee brand at the USPTO and CIPO (Canadian Intellectual Property Office). Grudgingly, along with other multinational coffee and other beverages, Starbucks is a participant in the franchising/licensing arrangement which the Ethiopian government now pursues with multinational interests on its brands of coffee. In June 2007, the Ethiopian government and Starbucks brokered a deal for the distribution and marketing of its specific GIs coffee brand. For Ethiopia's success story, see Alexia Garamfalvi, Ethiopian Coffee Trademark Dispute with Starbucks Runs Hot and Cold, Legar Times, Mar. 6, 2007, available at http://www.law.com/isp/article.jsp? id = 1173261800496. See also Ethiopian Coffee Licensing, http:// www.ethiopiancoffeenetwork.com/licensing.shtml (last visited July 12, 2008).

147. Samples of GIs success stories in developing countries include Darjeeling tea and Rooibos tea. Darjeeling tea is grown in Darjeeling, India, which is noted for its unique geographical and climatic condition. The tea, which is one of the world's most expensive, is noted for its unique flavor and aroma that compares to no other. Rooibos tea (aka red bush tea), grown only in the Cedarberg region and parts of Clanwilliam and Citrusdal in South Africa, is made by fermenting the sun-dried leaves of the red Rooibos bush and is associated with elements that prevent the death of brain cells and growth of cancer cells. See Soam, supra note 118, at 689-90; Sunder, supra note 4, at 303. 
protection beyond wines and spirits under TRIPS, developing countries, like India, have continued to take advantage of current rules to enact specific legislation on GIs, or to explore alternatives similar to GIs, such as trademarks or certification marks, for their geographically sensitive agricultural products. ${ }^{1+8}$

Unlike TKDL and DRs, GIs are a trademark-like protection that does not directly involve patents. ${ }^{199}$ However, it represents part of the broader scheme in which indigenous and local communities have taken the opportunity to push for the accommodation of their knowledge within the conventional intellectual property protection scheme. In today's postmodern environment, there is, on a global scale, a voracious appetitive for exoticism and romanticism around cultural products from "pristine" communities. This phenomenon is a practical translation of cultural cosmopolitanism in our increasingly networked and borderless commercial world. In a way, it also demonstrates the softening of the divisions along epistemic lines that characterize the relationship between traditional knowledge and Western scientism.

In the context of traditional medicine, specific medicines, and traditional medicinal practices, herbs or herbal preparations may be the subjects of GIs. But the standardization or certification required for the success of GIs and the intertwining of products, process, and services in traditional medicine go to show that GIs may have a challenging role to play in their protection. ${ }^{150}$ Nonetheless, the postmodern fascination with natural health products, naturaceuticals, or "food medicines," herbal medicines, and traditional medicine in general, is a further affirmation for cultural cosmopolitanism. Consequently, the market and intellectual property potential of traditional medicine-related products make GIs quite attractive.

Implementation of a GI regime in a developing country is a difficult and complex exercise. For instance, GI is a capital intensive endeavor, requiring an elaborate structure for the control of market power to nurture, brand, and popularize susceptible local products to ensure their global reach and acceptability.

148. In 1999, India enacted The Geographical Indications of Goods (Registration and Protection) Act as, perhaps, one of the most effective ways to protect that country's rich cultural heritage and an attempt to empower its diverse artisan and small scale agricultural communities "to remain in their villages, resisting the pull of city industries." Sunder, supra note 4, at 300 .

149. As a matter of distinction, trademark gives its owner the right to exclude others from using the trademark or sign of another, effectively distinguishing the goods and services of one enterprise from another, whereas "a geographical indication tells consumers that a product is produced in a certain place and has certain characteristics that are due to that place of production" and may be deployed by producers or manufacturers of that common region. WIPO, supra note 136 .

150. Eiland, supra note 39 , at 73 . 
Many indigenous and local communities whose products are subjects of GIs can hardly boast of the historically entrenched market niches and power associated with "champagne" and other products already protected by GIs. This situation requires some rethinking in those countries that have implemented GIs, such as India, as to whether manufacturing GI products should be limited strictly to historic communities, or be allowed to take place outside those communities. ${ }^{151}$ An argument in support of the latter is that $e x$-situ manufacture of GI products will accommodate migration-driven cultural cosmopolitanism. In addition, ex-situ manufacturing could also accommodate the possibility of franchising around products that are subjects of GIs. ${ }^{152}$ According to S. K. Soam, "it is a widely accepted fact that whenever people go to other places they bring along some product (such as sweets, textiles, handicrafts, artifacts, etc.) that has a specific reputation due to its association with its place of origin." ${ }^{153}$ Except where climatic, ecological, and cultural constraints are fundamental to the character and process of manufacture of a product, there is perhaps little reason why when people migrate, they should not take with them cultural practices and peculiar skills associated with the manufacture of GI products. ${ }^{154}$ These are important issues for consideration, especially given that countries that were reluctant converts to GIs, such as the United States, have embarked on an aggressive branding around GIs in ways that could undermine whatever benefit indigenous and local communities stand to gain in the use of GIs. To compete in the present GI environment, and to fully maximize the window of opportunity for GIs provided in the TRIPS Agree-

151. The Indian Geographical Indication of Goods (Registration and Protection) Act, 1999, prohibits the licensing of GIs and insists upon GI goods being exclusively limited to a specific geographic environment. Sunder, supra note 4, at 302. According to Sunder, "Such requirements and restrictions take a narrow view of traditional knowledge, [by] linking culture to land," and that such restrictions neglect the fact that "People move, intermarry, and change jobs. Culture flows with them. The GI Act does not recognize this dynamic nature of culture, ossifying authentic production in today's localities." Id. (footnotes omitted).

152. But see Calboli, supra note 118 , at 185 (arguing that GI cannot be licensed because their uniqueness strictly depends on their tie with the geographical place they identify).

153. Soam, supra note 118 , at 679.

154. Ironically, when immigrants carry on with products or manufacturing processes subject to GI, it can be argued that "[a]fter some time the link between the territory from which the products originated and their names [could be] forgotten, and the term that were used to identify these products [could enter] the common language as the generic name of the products rather than the name of their geographic origin." Calboli, supra note 118, at 198 (citing Molly Torsen, Apples and Oranges (and Wine): Why the International Conversation Regarding Geographic Indications is at a Standstill, 87 J. Pat. \& Trademark Off. Soc'y 31, 51-60 (2005)). 
ment, developing countries need to be pragmatic and responsive to keep up with the adoption and use of GIs in established economies.

In sum, despite their increasing patronage by developing countries in the post-TRIPs era, GIs seem to possess limited application to traditional medicine. Obviously, GIs speak to a different intellectual property regime than patents. However, as noted, the application of GIs to cultural products and their patronage reflects cultural cosmopolitanism, making GIs yet another demonstration of progress in the opening up of the intellectual property system to the pressures exerted by traditional knowledge, including traditional medicine, for appropriate recognition and admission into that regime on their own terms.

\section{Conclusion}

In the last decade since TRIPS and CBD, scholars, indigenous and local community activists, and various stakeholders have decried the irreconcilable nature of intellectual property with local knowledge forms. Much ink has been spilled in analyzing this perceived hopeless state of affairs in the search for a policy direction to empower local knowledge forms. Yet, little to no concrete results have emerged. In that preoccupation, it has been quite easy to ignore or lose sight of the fact that some progress, however infinitesimal, has been made in the effort to bring local knowledge closer to the ambit of the intellectual property system.

However, local knowledge continues to be frittered away in a unidirectional flow from local communities to Western industrial complexes, mainly through activities generally described as biopiracy. The skeptical and often dialectical relationship which had characterized the attitude of local knowledge custodians to the intellectual property system is gradually wearing thin for want of a more pragmatic approach. This is more so as the melding of knowledge systems awakens stakeholders to the reality of cultural cosmopolitanism and globalization. The hardened lines of division and categorization between knowledge systems are no longer strictly sustainable, given the traffic across knowledge and cultural systems around the world.

Both globalization and the challenge of biopiracy have opened new opportunities for pragmatic initiatives to breach and bridge the seemingly impenetrable barrier between local knowledge and the intellectual property system. Despite the dialectical disposition of local communities and some developing countries to the intellectual property system, there is notable progress in opening up local knowledge, especially traditional medicine, to that system. This is exemplified in the Indian-pioneered TKDL project which is basically an anti-appropriation initia- 
tive. The TKDL has recorded tremendous success in enhancing traditional medicinal knowledge within the international patent process. Also, by way of other nuanced policy initiatives, a number of countries, notably China, Japan, and Taiwan have adopted custom-specific strategies in bringing their traditional medicinal systems within the conventional patent framework. While there has been a tendency to tone down the theoretical and philosophical features of TCM in the attempt to open it into Western scientific ontology and the intellectual property system, Taiwan has proposed a unique and creative scheme through which it seeks to retain the theoretical essence of $\mathrm{CHM}$ within its patent regime.

In addition to these specific initiatives, developing countries are also willing to take advantage of TRIPS provisions on GIs and the ongoing debates around DRs to open up local knowledge to the intellectual property system. While strides in GIs and DRs are inchoate, both are means for demonstrating the reality of cultural cosmopolitanism. GIs and DRs have no direct bearing on traditional medicine, unlike the Indian TKDL and Taiwanese initiative. However, the interest and patronage they attract in developing countries and in indigenous and local communities are indicative of the overall paradigm shift that has occurred and that has positively impacted the hitherto hopeless state of frustration arising from the perceived quandary in reconciling local knowledge with the conventional patent system.

It is too early to examine the transformative impact of these initiatives in terms of their actual empowerment of local knowledge. Nonetheless, it is difficult to dismiss the symbolic essence of the initiatives in the overall thrust of cultural cosmopolitanism and the dialectics of knowledge transformation. Thus far, this development, though incremental and unpredictable in terms of sustainability, represents the first practical steps toward stretching the conceptual framework of intellectual property, especially the patent regime, to accommodate local knowledge. It demonstrates a concrete shift from the traditional refrain that intellectual property is irreconcilable with local knowledge. 